Thorax, 1980, 35, 490-495

\title{
Elastic recoil changes in early emphysema
}

\author{
G WAYNE SILVERS, THOMAS L PETTY, AND RAY E STANFORD
}

From the Division of Pulmonary Sciences, the Webb-Waring Lung Institute, and the Laboratory Service, $\vec{\circ}$ Veterans Administration Hospital, University of Colorado Health Sciences Center, Denver, Colorado, USA $\overrightarrow{\overrightarrow{.}}$

ABSTRACT An attempt was made to determine if emphysema and static lung recoil were related in a group of 65 excised human lungs. We studied 23 normal lungs, 24 lungs with an emphysema scorew of 5 or less, and 18 lungs with an emphysema score greater than 5 . A comparison of the percentage v of predicted elastic recoil revealed that both emphysema groups were significantly different from 8 normal lungs. In addition, the total lung capacities were significantly different between the threeo groups. In the group with an emphysema score greater than 5 we found a linear negative correlation between the extent of emphysema and percent of predicted elastic recoil at $90 \%$ total lung capacityE $(\mathrm{r}=-0.696, \mathrm{p}<0.01)$. We found a negative correlation between the percentage of predicted elastic recoil and the lung volume $(r=-0.612, p<0.01)$. We conclude that a significant loss of elastices recoil and a significant increase in total lung capacity occurs in the early stages of emphysema.

It is generally believed that the anatomical destruction of pulmonary tissue in emphysema is closely related to the functional loss of elastic recoil. Thurlbeck ${ }^{12}$ has challenged this concept in recent articles and presents an alternative hypothesis that emphysema and elastic recoil are related only coincidentally. If the traditional view is correct and emphysema and elastic recoil are related as cause and effect, a good correlation between elastic recoil and emphysema should be present.

\section{Methods}

Excised human lungs were obtained from necropsies performed at either Colorado General Hospital or the Denver Veterans Administration Hospital. Lung specimens were chosen which appeared free of significant disease other than emphysema. Lungs that were later found on microscopic examination to have any pathological process other than emphysema that involved greater than $10 \%$ of the lung were eliminated from the study. This experimental protocol was completed within $\mathbf{4 8}$ hours of death or of cessation of mechanical ventilation in the case of cadaveric transplant donors.

Lungs were cannulated and inflated with air.

Address for reprint requests: G Wayne Silvers, Box C272, University of Colorado, Health Sciences Center, 4200 East 9th A venue, Denver. Colorado 80262, USA.
Leaks were repaired by ligature. Only specimen that could be made airtight were used in this study. The lungs, while floating on a bed of normal saline, were inflated three times witlB air to a pressure of 20 to $22 \mathrm{~cm}$ of $\mathrm{H}_{2} \mathrm{O}$ ance allowed to deflate passively. A static pressure? volume curve was constructed by inflating the lung with air to $20 \mathrm{~cm} \mathrm{H}_{2} \mathrm{O}$ and deflating? by removing air in $2 \mathrm{~cm} \mathrm{H}_{2} \mathrm{O}$ pressure decre $\tilde{x}$ ments. Pressure was measured on a U-tube wate manometer. Thirty seconds at each pressure measurement were allowed to ensure equiliọ bration. Minimal volume, the volume of gas remaining in the lung at zero transpleural pres은 sure, was determined by water displacement and subtracting the volume of the tissue, assuming the specific gravity of lung tissue to be $1 \cdot 0$.

The pressure-volume curves were corrected for gas compression. Total lung capacity (TLCS was calculated by assuming that the left lunsw represents $45 \%$ and the right lung $55 \%$ of the total lung volume. The total lung capacity wass expressed as a percent of predicted total luns్s capacity, using the predicted values of Goldman and Becklake ${ }^{3}$ for females and the values ofo Boren et $a^{4}$ for males.

The lungs were fixed in inflation at a pressure of $20 \mathrm{~cm} \mathrm{H}, \mathrm{O}$ with $1.8 \%$ neutral buffered gluta 8 raldehyde and sectioned sagitally at $10 \mathrm{mmo}$ intervals. The lungs were studied histologically using the methods of Mitchell et al. ${ }^{5}$ 
An emphysema score was established for each lung by a modification of the method of Thurlbeck et $a l^{,}{ }^{6}$ using a series of 20 standardised photographs representing differing degrees of destruction. The score for the degree of destruction was increased by 5,10 , or 20 points, respectively, if mild, moderate, or severe fenestration of alveolar walls in grossly normal portions of lung was noted microscopically. Only five of the 65 cases studied were altered by the fenestration reading. All specimens were scored indepently of the other studies.

\section{Results}

The lungs were divided into three groups based on the amount of anatomical emphysema present. The normal group consisted of 23 lungs without any discernible emphysema by gross or microscopic observation. The emphysematous lungs were divided into two groups, one with emphysema score of trace to 5 , and the other with score greater than 5 . The greater than 5 group ranged from a score of 10 to 85 with a mean of $39 \cdot 7 \pm 4.9 \mathrm{SEM}$. The sex and age distribution of each group is shown in table 1. Because of obvious age differences among the groups studied, we have expressed elastic recoil as a percentage of predicted recoil at specific volumes of total lung capacity (Pst(l) $x$, where $\mathrm{x}=\%$ total lung capacity). We have used the

Table 1 Sex and age distribution of three groups studied

\begin{tabular}{lccc}
\hline & Normal & $\begin{array}{c}\text { Trace-grade } \\
\text { 5 emphysema }\end{array}$ & $>$ Grade 5 emphysema \\
\hline Men & 14 & 17 & 16 \\
Women & 9 & 7 & 2 \\
Total & 23 & - & 18 \\
Age (yr) & $33.0 \pm 15.9$ & $47.8 \pm 14.6$ & $65.4 \pm 12.7$ \\
\hline
\end{tabular}

Table 2 Percentage of predicted static lung recoil $\pm S E M$

\begin{tabular}{|c|c|c|c|}
\hline$\% T L C$ & Normal & $\leqslant$ Grade 5 emphysema & $>$ Grade 5 emphysema \\
\hline $\begin{array}{l}\text { After d } \\
50 \\
60 \\
70 \\
80 \\
90\end{array}$ & $\begin{array}{l}\text { lata of Knuc } \\
44 \cdot 3 \pm 2 \cdot 9 \\
48 \cdot 9 \pm 2 \cdot 8 \\
54 \cdot 0 \pm 2 \cdot 7 \\
59 \cdot 5 \pm 2 \cdot 3 \\
64 \cdot 8 \pm 1 \cdot 7\end{array}$ & $\begin{array}{l}\text { son et al } \\
29 \cdot 2 \pm 2 \cdot 6^{*} \\
34 \cdot 9 \pm 2 \cdot 4^{*} \\
42 \cdot 6 \pm 2 \cdot 2^{*} \\
49 \cdot 9 \pm 1 \cdot 9^{*} \\
581 \pm 1 \cdot 5^{*}\end{array}$ & $\begin{array}{l}16 \cdot 0 \pm 1 \cdot 8^{* \dagger} \\
22 \cdot 0 \pm 2 \cdot 2^{*+} \\
27 \cdot 7 \pm 2 \cdot 2^{*+} \\
36 \cdot 1 \pm 1 \cdot 9^{*+} \\
49 \cdot 8 \pm 1 \cdot 6^{*+}\end{array}$ \\
\hline $\begin{array}{l}\text { From E } \\
50 \\
60 \\
80\end{array}$ & $\begin{array}{l}\text { Bode et al } \\
56 \cdot 0 \pm 3 \cdot 0 \\
55 \cdot 8 \pm 2 \cdot 4 \\
62 \cdot 2 \pm 2 \cdot 1\end{array}$ & $\begin{array}{l}42 \cdot 2 \pm 3 \cdot 2 * \\
46 \cdot 2 \pm 2 \cdot 5 \ddagger \\
56 \cdot 0 \pm 1 \cdot 7 \ddagger\end{array}$ & $\begin{array}{l}38 \cdot 2 \pm 6 \cdot 1^{*} \\
40 \cdot 2 \pm 4 \cdot 8^{*} \\
45 \cdot 8 \pm 2 \cdot 3^{*}+\end{array}$ \\
\hline
\end{tabular}

* Different from normal $p<0.01$.

+ Different from $\leqslant$ grade 5 emphysema $p<0.01$.

$\ddagger$ Different from normal $p<0.05$.
Table 3 Percentage of predicted $h$ value $\pm S E M$ (after Turner et al ${ }^{11}$ )

\begin{tabular}{lll}
\hline Normal & $\leqslant$ Grade 5 emphysema & $>$ Grade 5 emphysema \\
\hline $54 \cdot 3 \pm 2 \cdot 6$ & $43.5 \pm 2 \cdot 9 \dagger$ & $28 \cdot 2 \pm 6 \cdot 3^{*}$
\end{tabular}

* Different from normal $p<0.01$.

+ Different from normal $p<0.02$.

data of Knudson et $a l^{7}$ and of Bode $e t a l^{8}$ for predicted Pst(1).

By one-way analysis of variance, ${ }^{9}$ the elastic recoil was decreased in the trace-grade 5 group compared to the normal group $(\mathrm{p}<0.01)$ at all volumes studied and in the grade 5 or greater group was statistically different from normal and the trace-grade 5 group $(\mathrm{p}<0.01)$ at all volumes examined when using regression curves obtained from the data of Knudson et al, ${ }^{7}$ (table 2). When using the prediction data of Bode et al, ${ }^{8}$ the two emphysema groups were statistically different from normal at Pst(1) 50, 60, and $80 \%$ of total lung capacity (table 2). Only at Pst(1) $80 \%$ was the greater than 5 emphysema group significantly different from trace-grade 5 emphysema group.

The expiratory pressure-volume curves were fitted with a single cxponcritial function after the method of Salazar and Knowles. ${ }^{10}$ To correct for age we have used the data of Turner et al. ${ }^{11}$ A multiple comparisons test reveals a significant difference when comparing the two emphysema groups with the normal lungs $(p<0.03)$ (table 3$)$. Surprisingly, there was no significant difference between the two emphysema groups.

The total lung capacities were different for each group (fig 1). An analysis of variance shows that the percentage predicted TLC differed significantly $(p<0.02)$ between the three groups.

In order to gain some insight into the relationship of emphysema and elastic recoil, we correlated the extent of emphysema against Pst(1) $x$ in the greater than grade 5 emphysema group of lungs. There was a negative correlation which was significant $(p<0.05)$ at Pst $(1) 80,90 \%$ of TLC using the data of Knudson et al for predicted data. The plot of the data at Pst(1) $90 \%$ is shown in fig 2 .

When the volume of the lungs expressed as a percentage of predicted TLC is related to elastic recoil as a percentage of predicted using the regression curves of Knudson et al there is a significant correlation $(p<0.05)$ at Pst(l) 50 and $90 \%$ of TLC. The plot of the data at Pst(1) $90 \%$ is shown in fig 3.

Our data were also compared with Niewoehner et $a l^{12}$ by obtaining $\alpha_{1}$ which describes the elastic 


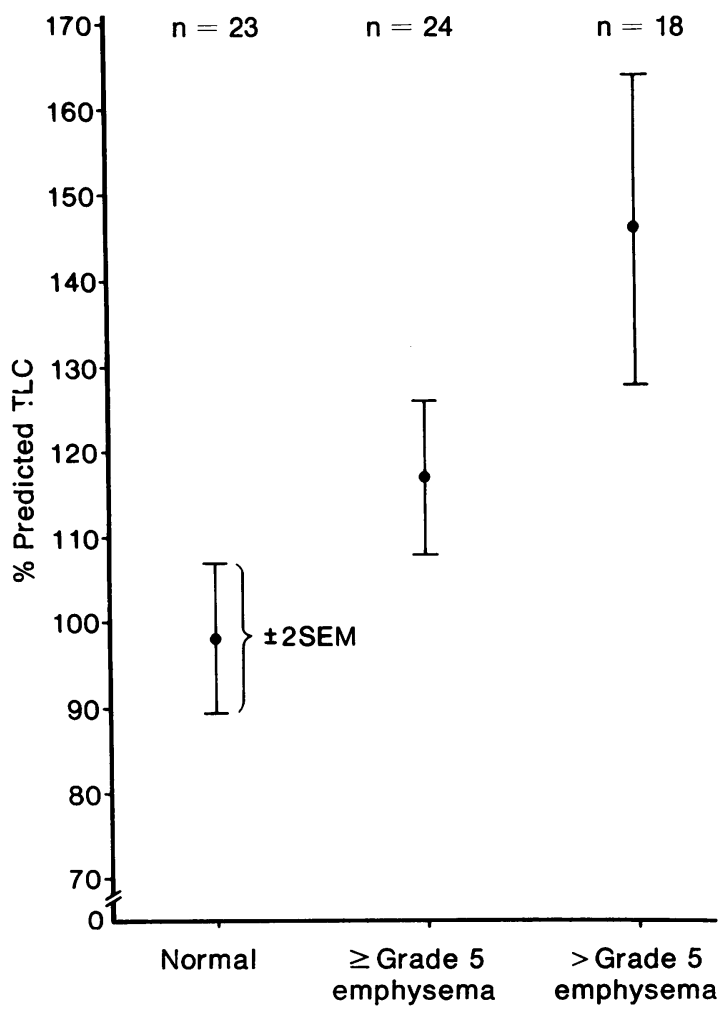

Fig 1 Mean percentage predicted total lung capacity $\pm S E M$ is shown for the three lung groups examined $(p<0.02$ between all three groups).

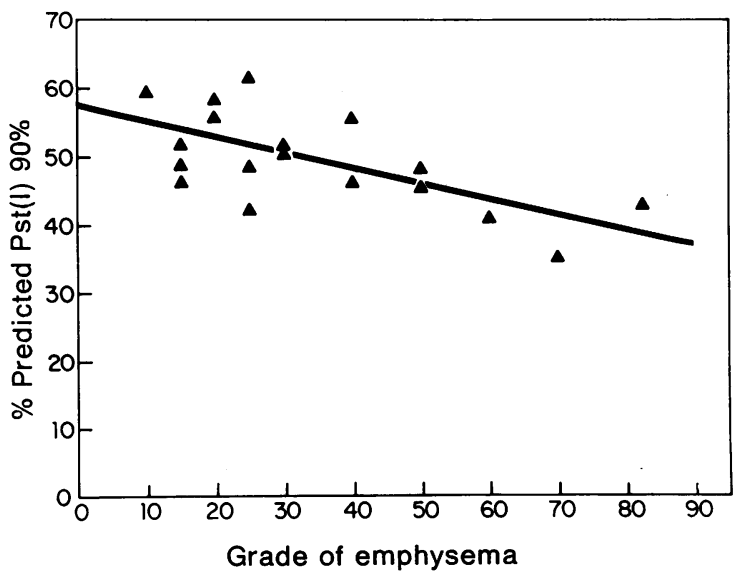

Fig 2 Percentage of predicted elastic lung recoil at $90 \%$ total lung capacity after Knudson et al is plotted against the score of emphysema for the $>5$ emphysema group $(r=-0.696, p<0.01, \Delta=>$ grade 5 emphysema $)$.

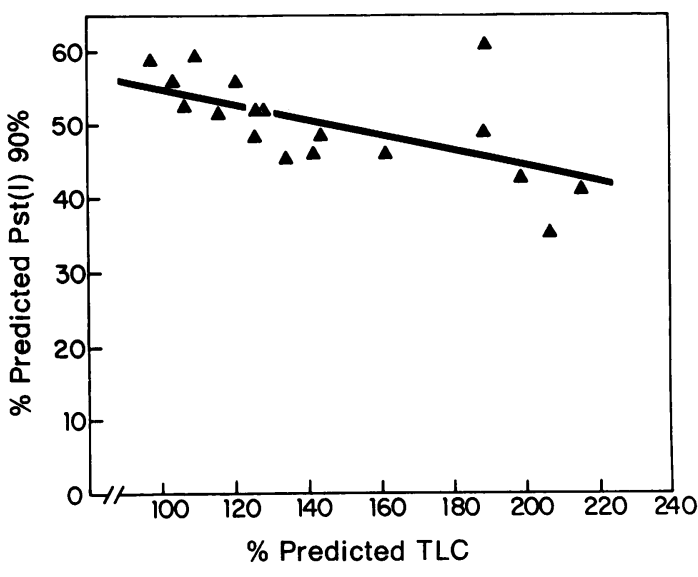

Fig 3 Volumes of the lungs as a percentage of predicted total lung capacity (TLC) is plotted against elastic recoil as a percentage of predicted elastic recoil at $90 \%$ total lung capacity $(r=-0.612, p<0.01, \Delta=>$ grade 5 emphysema). The predicted recoil values are after Knudson et al. ${ }^{?}$

properties of a lung independent of lung size, (fig 4). Nine of the greater than 5 emphysema groups and 14 of the less than grade 5 emphy- 0 sema group were below the 2 SEE for normalö lungs.

\section{Discussion}

Frank and associates found that older subjectso demonstrated less lung elastic recoil ${ }^{13}$ than $x$ younger subjects. ${ }^{14}$ Permutt and Martin, ${ }^{15}$ how- 극 ever, concluded that there was no change of elastic recoil of the lung with age. Other studies? since then have concluded that the decrease in lung elastic recoil is a function of aging 781116 은 19 in living subjects as well as studies of excised normal human lungs. ${ }^{12} \mathrm{~A}$ decrease in elastic recoil has also been shown to be associated with advanced anatomical emphysema ${ }^{20-22}$ as well as in mild emphysema from excised lungs. ${ }^{12}$ Our study would support these earlier observationsw but raises the question whether emphysema iহ the sole cause of the loss of elastic recoil ing addition to normal aging.

The data we obtained from the excised lungs are comparable with data from live subjects. We have compared the Pst(1) $50 \%$ obtained from? all lungs against the transpulmonary pressure ae $50 \%$ of the total lung capacity reported by Turner et $a l^{11}$ (fig 5). All of the points fall at oe or below the regression line, and all but threes are within the -2 SEE. Although the data of 


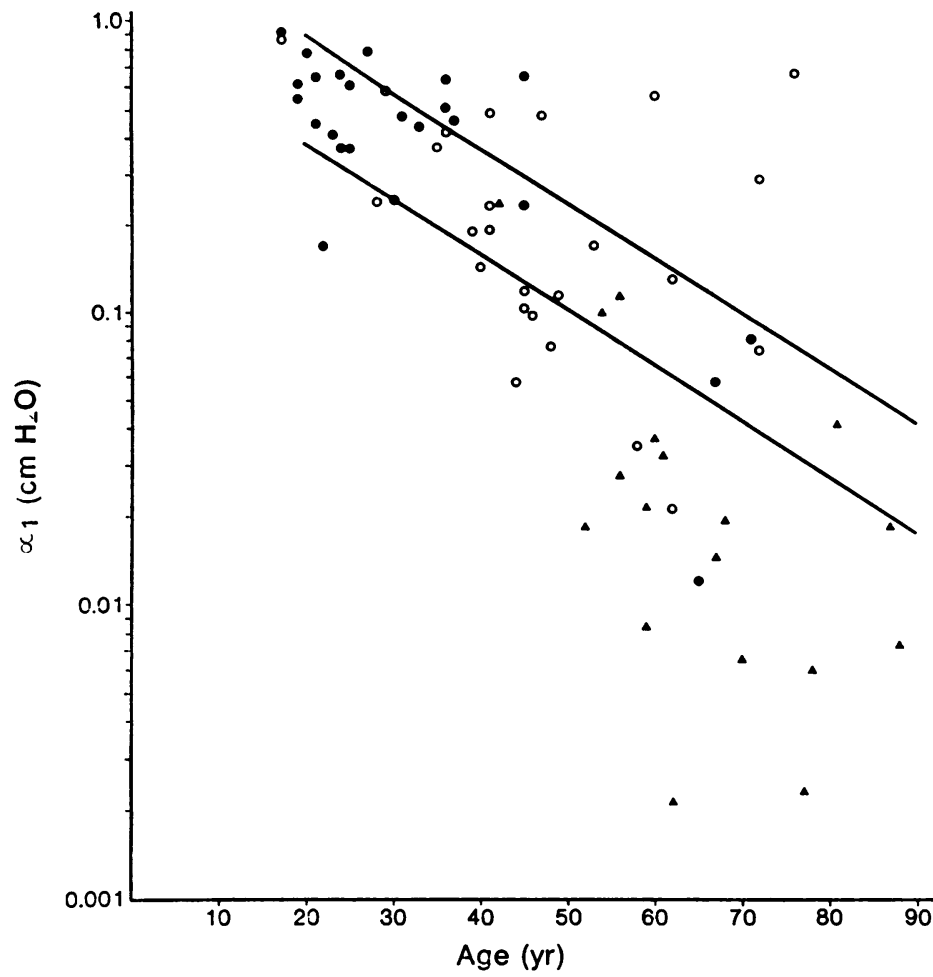

Fig 4 Semilogarithmic plot of $\alpha_{1}$ related to age in all lungs studied $(O=$ normal, $\mathrm{O}=\leq$ grade 5 emphysema, $\Delta=>$ grade 5 emphysema). Solid lines represent $2 S E E$ of the mean for normal lungs reported by Niewoehner et al. ${ }^{12}$

Turner and associates ${ }^{11}$ included smokers and former smokers and therefore may contain data from subjects with mild emphysema. The purpose of this comparison is to demonstrate that the values we obtained are within limits seen in living subjects. These data are also similar to values obtained by Niewoehner et $a^{12}$ from ex- cised normal human lungs.

The low elastic recoil in excised lungs when compared to intact lungs suggests that excised lung TLC may be greater than in vivo TLC. Examination of the TLC of the normal lungs we have examined would indicate that our measurements of TLC agree very well with predicted

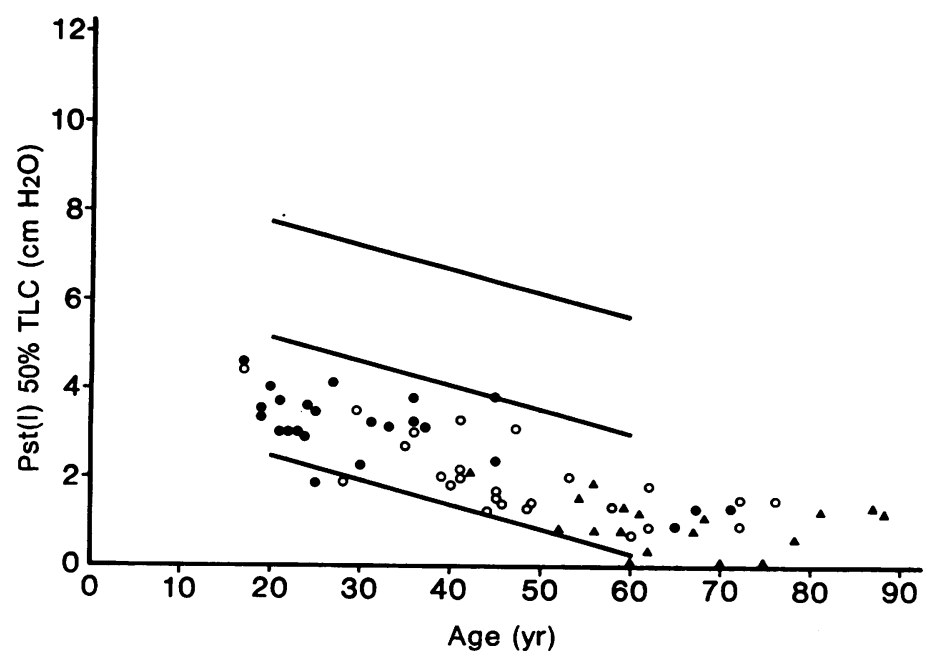

Fig 5 Comparison of elastic lung recoil at $50 \%$ total lung capacity and age, symbols as in fig 4. Solid lines are the mean and $\pm S E E$ of Turner et al. ${ }^{11}$ 
values. Thurlbeck concluded from a study of the comparison of TLC of human lungs fixed at necropsy with formalin at transpulmonary pressure of $25 \mathrm{~cm}$ of water were similar to their TLC assessed radiologically. ${ }^{2}$ That study included lungs without emphysema as well as lungs with emphysema ranging from a score of 1 to greater than 65 . Niewoehner and associates ${ }^{12}$ have commented that excised lung pressure volume characteristics may more realistically describe the properties of the lung since chest wall characteristics and oesophageal balloon error are eliminated.

Since there is a difference in the sizes and volumes of the lungs we have studied, we have also used the method of Niewoehner and associates $^{12}$ which expresses the elastic properties of a lung independent of lung size and volume, $\alpha_{1}$ (fig 5). Our study would support the observations of Niewoehner et $a^{12}$ that pressure-volume curve differences can be detected in mild emphysema and this difference is caused by elastic characteristics.

Our study tested the hypothesis that mild emphysema can be detected by pressure-volume curves by comparing elastic recoil data from normal subjects with lungs with only minimal anatomic emphysema-that is, grade 5 or lesscompared in turn to a group with various degrees of advanced emphysema. We found that the group with minimal emphysema did have reduced elastic recoil compared to normal subjects when we expressed the static lung recoil as a percentage of predicted. It would thus appear from our data that changes in elastic recoil occur early with anatomical emphysema.

If emphysema and elastic recoil are related as cause and effect then a good correlation between the amount of emphysema and the loss of elastic recoil should be present. Linear correlations made between the grade of emphysema and the percentage of predicted elastic recoil at Pst(1) $\mathbf{9 0} \%$ did reveal a significant negative correlation $(r=-0.696)$, but this correlation was not as strong as one would have expected if the loss of elastic recoil was directly related to the extent of emphysema. The predicted elastic recoil used for these correlations were after Knudson et al. ${ }^{7}$

Thurlbeck has speculated that since mean linear intercept was increased in a group of excised human lungs with mild emphysema compared with normal lungs, but the mean alveolar surface area corrected for an arbitrary lung volume of five litres was not altered, this suggested an increased lung volume. ${ }^{23}$ More recently he has suggested that a change in lung volume in patients with equivocal or mild degrees of anatomical emphysema could account for the? mechanical property changes described with age in living subjects. ${ }^{2}$ The data from the present? study would support Thurlbeck's notion-that is to say, the increase in lung volume in the group with minimal emphysema is out of proportions to the extent of emphysema. The greater volume of the lungs noted at a given distending pressure must be derived from altered elasticity.

Although we found differences in percentage predicted TLC among the three groups examined the possibility remained that excised humarf lungs demonstrate an increase in percentage pre- $-v$ dicted TLC with age. Since age differences wereे present in the groups studied we tested the normal group with respect to percentage predicteof TLC and age. No significant correlation was found $(r=0.13, p>0.05)$. It is therefore possible that changes in elastic recoil and lung volume may precede the development of emphysema afo judged by light microscopy. The greater than grade 5 group did show a correlation with the percentage predicted TLC and score of emphys sema $(r=0.618, p<0.01)$. This agrees with Thurl beck's data. ${ }^{2}$

The cause of changes in elastic recoil in adul human non-emphysematous lungs is yet to be fully understood. Previous chemical analysis of lung elastin content of human lungs have de monstrated either an increase or constant amoun $\bar{E}$ of elastin in aging lungs. ${ }^{24-27}$ Recent studies in aging mice however, suggest that lung elastiro content decreases with age. ${ }^{28}$ Those author believed that pseudoelastin could account for the findings in human lungs where elastin conten was found to be increased or remained constang with age. This suggests that elastin in human lungs may decrease with age.

A study of elastic fibres of normal human lungs and lungs with mild emphysema, 1-10\% by point count, demonstrate that no differences in total fibre length and diameter exist. ${ }^{29}$ Thi $\$$ would indicate that loss of elastic recoil is nof the result of a simple loss of elastic fibres.

Our results show that elastic recoil in lunge with minimal emphysema is reduced and the totaf lung capacity is increased when compared if normal subjects. Since these changes are out o\& proportion to the degree of emphysema presento we conclude that the loss of elastic recoil is no $\bar{b}$ caused entirely by emphysema. Our results sug gest that emphysema and elastic recoil are no related as cause and effect and that they may b]్ర related only coincidentally.

This notion is also consistent with the concepto 
and studies of Laros and associates ${ }^{30}$ that elastic recoil may be altered by subtle changes in elastic junctions, connections, and abnormalities in the ground substance of the connective tissue of the lung.

We would like to thank Alan Suzuki for the statistical analysis used in the paper. This work was supported by National Health Grants HL22723 and HL07085.

\section{References}

1 Thurlbeck WM. Aspects of chronic airflow obstruction. Chest 1977; 72:341-9.

2 Thurlbeck WM. Post-mortem lung volumes. Thorax 1979; 34:735-9.

3 Goldman HI, Becklake MR. Respiratory function tests. Normal values at medium altitudes and the prediction of normal results. Am Rev Tuberc 1959; 79:457-67.

4 Boren HB, Kory RC, Syner JC. The Veterans Administration-Army Cooperative Study of Pulmonary Function. II. The lung volume and its subdivision in normal man. Am J Med 1976; 41:96-114.

5 Mitchell RS, Stanford RE, Johnson JM, Silvers GW, Dart G, George MS. The morphologic features of the bronchi, bronchioles, and alveoli in chronic airway obstruction: a clinicopathologic study. Am Rev Respir Dis 1976; 114:137-45.

6 Thurlbeck WM, Dunnill MS, Hartung W, Heard BE, Heppleston AG, Ryder RC. A comparison of three methods of measuring emphysema. Hum Pathol 1970; 1:215-26.

7 Knudson RJ, Clark DF, Kennedy TC, Knudson DE. Effect of aging alone on mechanical properties of the normal adult human lung. $J A p p l$ Physiol: Respir Environ Exercise Physiol 1977; 43:1054-62.

8 Bode FR, Dosman J, Martin RR, Ghezzo H, Macklem PT. Age and sex differences in lung elasticity, and in closing capacity in non-smokers. J Appl Physiol 1976; 41:129-35.

9 Snedecor GW, Cochran WG. Statistical methods. Sixth edition. Ames, Iowa: Iowa State University Press, 1967: 258-98.

10 Salazar E, Knowles JH. An analysis of pressurevolume characteristics of the lungs. $J A p p l$ Physiol 1964; 19:97-104.

11 Turner JM, Mead J, Wohl ME. Elasticity of human lungs in relation to age. $J$ Appl Physiol 1968; 25:664-7.

12 Niewoehner DE, Kleinerınan JR, Liotta S. Elastic behaviour of post-mortem human lungs: effects of aging and mild emphysema. J Appl Physiol 1975; 39:943-9.

13 Frank NR, Mead J, Ferris BG Jr. The mech- anical behaviour of the lungs in healthy elderly persons. J Clin Invest 1957; 36:1680-7.

14 Frank NR, Mead J, Siebens AA, Storey CF. Measurements of pulmonary compliance in seventy healthy young adults. $J$ Appl Physiol 1956; 9:38-42.

15 Permutt S, Martin HB. Static pressure-volume characteristics of lungs in normal males. $J A p p l$ Physiol 1960; 15:819-25.

16 Pierce JA, Ebert RV. The elastic properties of the lungs in the aged. $J$ Lab Clin Med 1958; 51: 63-71.

17 Cohn JE, Donaso HD. Mechanical Properties of lung in normal men over 60 years old. J Clin Invest $1963 ;$ 42:1406-10.

18 Mittman C, Edelman NH, Norris AH, Shock NW. Relationship between chest wall and pulmonary compliance and age. J Appl Physiol 1965; 20:1211-6.

19 Gibson GJ, Pride NB, O'Cain C, Quagliato R. Sex and age differences in pulmonary mechanics in normal nonsmoking subjects. J Appl Physiol $1976 ; 41: 20-25$.

20 Finucane KE, Colebatch HJH. Elastic behaviour of the lung in patients with airway obstruction. J Appl Physiol 1969; 26:330-8.

21 Park SS, Janis M, Shim CS, Williams MH Jr. Relationship of bronchitis and emphysema to altered pulmonary function. Am Rev Respir Dis 1970; 102:927-36.

22 Stead WW, Fry DS, Ebert RV. The elastic properties of the lung in normal men and in patients with chronic pulmonary emphysema. J Lab Clin Med 1952; 40:674-81.

23 Thurlbeck WM. Internal surface area and other measurements in emphysema. Thorax 1967; 22: 483-96.

24 Pierce JA, Ebert RV. Fibrous network of the lung and its change with age. Thorax 1965; 20: 469-76.

25 Pierce JA, Hocott JB. Studies on the collagen and elastin content of the human lung. $J$ Clin Invest 1960; 39:8-14.

26 Scarpelli V, Repetto M. The elastic content of the lung in relation to age. Ital J Biochem 1959; 8:169-72.

27 Wright GW, Kleinerman J, Zorn EM. The elastin and collagen content of normal and emphysematous human lungs. Am Rev Respir Dis 1960; 81:938.

28 Ranga V, Kleinerman J, Sorensen J. Age-related changes in elastic fibers and elastin of lung. $A m$ Rev Respir Dis 1979; 119:369-76.

29 Niewoehner DE, Kleinerman JR. Morphometoric study of elastic fibers in normal and emphysematous human lungs. Am Rev Respir Dis 1977; 115:15-21.

30 Laros CD, Kuyper CMA. The pathogenesis of pulmonary emphysema (II). Respiration 1976; 33:325-48. 